\title{
Actors and networks in resource conflict resolution under climate change in rural Kenya
}

\author{
Grace W. Ngaruiya ${ }^{1}$ and Jürgen Scheffran ${ }^{2}$ \\ ${ }^{1}$ Department of Plant Sciences, Kenyatta University, Conservation Biology Section, Nairobi, Kenya \\ ${ }^{2}$ Institute of Geography, University of Hamburg, Research Group "Climate Change and Security”, \\ Hamburg, Germany \\ Correspondence to: Grace W. Ngaruiya (ngaruiya.gracew@ku.ac.ke)
}

Received: 15 December 2015 - Published in Earth Syst. Dynam. Discuss.: 18 January 2016

Accepted: 29 March 2016 - Published: 10 May 2016

\begin{abstract}
The change from consensual decision-making arrangements into centralized hierarchical chieftaincy schemes through colonization disrupted many rural conflict resolution mechanisms in Africa. In addition, climate change impacts on land use have introduced additional socio-ecological factors that complicate rural conflict dynamics. Despite the current urgent need for conflict-sensitive adaptation, resolution efficiency of these fused rural institutions has hardly been documented. In this context, we analyse the Loitoktok network for implemented resource conflict resolution structures and identify potential actors to guide conflict-sensitive adaptation. This is based on social network data and processes that are collected using the saturation sampling technique to analyse mechanisms of brokerage. We find that there are three different forms of fused conflict resolution arrangements that integrate traditional institutions and private investors in the community. To effectively implement conflictsensitive adaptation, we recommend the extension officers, the council of elders, local chiefs and private investors as potential conduits of knowledge in rural areas. In conclusion, efficiency of these fused conflict resolution institutions is aided by the presence of holistic resource management policies and diversification in conflict resolution actors and networks.
\end{abstract}

\section{Introduction}

Most African ethnic groups coexist peacefully with high degrees of mixing through inter-ethnic marriage, economic partnerships, and shared values that have been nurtured patiently over millennia (Aapengnuo, 2010). As a result, the management of conflicts before colonization was guided by indigenous governance institutions that established consensual decision-making arrangements at the grassroots (ECA, 2007). This administrative role was later transferred to chieftaincies created by colonial governments that sought to impose hierarchical rule on its subjects (Osaghae, 1989). After independence, many African countries opted to maintain colonial administrative structures and chieftaincy. To increase effectiveness in rural governance, local chiefs were elevated to custodians of customary law and communal assets, with a responsibility to dispense justice, resolve conflicts and enforce contracts (ECA, 2005). This action created co-management regimes composed of diverse stakeholders, representing divergent interests and interacting directly over a period of time to resolve a specific conflict within their locality (Brunner et al., 2005).

However, the seemingly "stable" African conflict dialogue is currently becoming complicated through additional socioecological factors from unpredictable climatic conditions (Carius, 2009). There is a broad scientific debate whether and how climate change may act as a "threat-multiplier" and will increase resource conflicts in sub-Sahara Africa (Lobell et al., 2008) among resource-dependent rural communities with low adaptive capacity (AMCEN, 2011; Haldén, 2007; WRI et al., 2005). For clarity, a resource conflict is defined in a wide sense as a situation whereby two or more parties (individuals or groups) have or perceive to have, (a) incompatible livelihood goals and interests, or (b) are in direct resource competition with each other and act upon these differences (UNEP, 2009, 2011). 
Adaptation measures addressing impacts of climate change on rural livelihoods have already been instituted globally to moderate potential damages and/or exploit beneficial opportunities (IPCC, 2007). But rigid demarcation into sectoral tasks of adaptation programmes can fall short when it comes to conflict. Thus, a more systematic, integrated approach is necessary to meaningfully incorporate existing conflict dynamics - as well as overarching socio-political and economic conditions - into the design of adaptation measures. This creates the need for conflict-sensitive adaptation strategies to enhance sustainable development (Tänzler et al., 2013). Conflict-sensitivity refers to approaches and measures that display cognisance of how climate change can cause conflicts; climate adaptation projects themselves can contribute to conflict, and adaptation measures would operate in conflict zones (Yanda and Bronkhorst, 2011). Such knowledge allows planners and decision-makers to address current vulnerabilities and development priorities, while aiming to ensure long-term sustainability and peace through a basic understanding of future projections (Yanda and Bronkhorst, 2011).

Consequently, this article seeks to address two knowledge gaps through this paper. First, effectiveness of the fusion between indigenous mechanisms with conventional and western conflict resolution approaches is still in question (ECA, 2007). Second, few studies have documented actual rural structures and mechanisms used to resolve resource conflicts in the sub-Saharan grassroots (Hyden et al., 2005). To this end, we critically evaluate conflict resolution mechanisms of the water, agriculture and wildlife sectors of Loitoktok Sub-County in Southern Kenya. We then use the brokerage concept under social network analysis to identify central conflict resolution actors with the potential to guide implementation of conflict-sensitive adaptation (Yanda and Bronkhorst, 2011). We hypothesize that the presence of diverse stakeholders in the conflict-resolution process contributes to high potential success in implementation of conflict-sensitive adaptation in Loitoktok. Our discussion intends to further clarify local conflict dynamics influencing adaptive capacity, social cohesion and rural development in Kenya, as well as to contribute to the climate-security discourse in Africa.

The paper begins with a brief summary on the evolution of resource governance in Africa. Then it elucidates capacity challenges of current rural resource governance in dealing with potential climate-driven conflicts in sub-Saharan Africa and expounds on the use of social network theory in diagnosing resource governance. Thirdly, a description is given of the case study area of Loitoktok and the method used for collecting and analysing social network data. The results and discussion are thereafter presented based on identified conflict resolution mechanisms at the grassroots and their potential in the climate adaptation discourse. A brief conclusion is given on key highlights from the study.

\section{Evolution of resource governance in Africa}

Governance is defined as "the effective management of public affairs through the generation of a regime (set of rules) accepted as legitimate, for the purpose of promoting and enhancing societal values sought by individuals and groups" (Hyden et al., 2005). It takes place through diverse institutions in a society, whereby, an institution is likewise defined as an enduring collection of formal laws and informal rules, norms, customs, codes of conduct, and organized practices that shape and govern human interaction (IDRC, 2009).

African indigenous institutions of governance were altered radically by colonial occupation that established a centralized governance system through the formalized chieftaincy tactic that became the foundation of post-colonial governments of many African countries (Cheka, 2008). After independence, the chieftaincy mandate was further altered during fundamental restructuring of socioeconomic systems by African political entities (ECA, 2007). Maintenance of the chieftaincy position was disputed by some who were concerned with rapid growth and transformation of African economies. For example, the late Tom Mboya quoted in Osaghae (1989) stated

\section{Chieftaincy impedes the pace of development as it reduces the relevance of the State in the area of social services.}

Proponents of the chieftaincy stratagem highlighted differences between the two systems that were clearly seen especially during conflict resolution, for example the colonial (modern) legal system operates on the basis of an adversarial approach while the traditional decision-making systems function on the basis of consensual decision-making and reconciliation arrangements (ECA, 2007; IDRC, 2009; IIDEA, 2011). Furthermore, since traditional institutions are indispensable for political transformation in Africa, post-colonial governments opted to incorporate indigenous knowledge into local administration regulations to increase positive perception of the government by the masses (ECA, 2007).

Similarly, natural resources are embedded in a shared social space where complex and unequal relations are established among a wide range of social actors, e.g. in the case of the production of primary products, there is a mix of agroexport producers and farmers, ethnic minorities, government agencies and others (Mwanika, 2010). However, the "onesize-fits-all" governance approach introduced by colonialists gave poor outcomes especially in the water, wildlife and forest sectors, thereby necessitating establishment of rural participatory resource management approaches to promote community-based resource management and conservation in developing countries (Berkes, 2004). The inclusion of indigenous institutions and knowledge was important because they guide how people negotiate access to resources and reduce (though not avoid altogether) negative effects of conflict or drought (Eriksen and Lind, 2009). Apart from indige- 
nous institutions, many developing countries are currently implementing poverty-reduction schemes that target the unemployed and marginalized groups. In Kenya, the state has established among others the Revolving Fund for women and youth community groups seeking to access business funds to improve their living standards (Ngaruiya and Scheffran, 2013).

Consequently, three main types of institutional governance systems are active in rural Africa.

Traditional institutions are defined as a power, permission or an institution emanating from indigenous authority that draws its legitimacy, whether wholly or partially, from tribal/ethnic/cultural values of a group of people that share them (Cheka, 2008). Such traditional institutions have either centralized or decentralized governance systems. Centralized systems had kings and monarchs such as the Abyssinia (Ethiopia), Buganda (Uganda) and Ashanti (Ghana) while decentralized systems comprise a council of elders found among the Kikuyu and Maasai (Kenya), the gada (age-set) system of the Oromo in Ethiopia, or the Ibo village assembly in Nigeria (ECA, 2007).

Formal institutions are state-sponsored institutions that were mostly inherited from colonialism and constitute the written or codified rules such as the constitution, judiciary laws, organized markets, and property rights (IDRC, 2009; Mowo et al., 2013).

Informal institutions are the patterns of interdependence and actions among individuals who build themselves into different structural configurations to improve their living conditions or enhance resource exploitation. The actor linkages formed across the community vary by religion, ethnic identity, mode of production and are manifested as social networks (Prell et al., 2010).

When formal, informal and traditional institutions complement each other at different prefectures and different tiers, stakeholders are able to integrate diverse but relatable sources of knowledge to broaden resolution alternatives that might otherwise have been missed (Irwin et al., 2007). However, institutional incoherence is a major obstacle to effective governance. Incoherence occurs when governance institutions become incompatible to each other, with consequences such as hindrances in decision-making, wastage of financial resources or even deepened conflicting relationships at the grassroots (IDRC, 2009; Mowo et al., 2013). A practical incoherence example is seen in local adaptive capacity projects that are characterized by conflicting, overlapping mandates and dysfunctional arrangements in inter-agency integration as a result of weak coordination that subsequently gives poor outcomes (Madzwamuse, 2010). In relation to this study, effective resource conflict governance calls for incorporation of indigenous knowledge with a formal conflict resolution institution to create flexible systems of resource management termed as adaptive co-management systems. These systems become tailored to specific places and situations and are supported by and work with various organizations at different levels (Folke et al., 2005). Furthermore, effective adaptive co-management must involve multiple stakeholders to enhance governance outcomes because local people know each other better, have more rapport and sense of belonging that creates opportunities for cooperation and collective action, for managing natural resources on a self-ruling and self-sufficient basis at the grassroots (Mowo et al., 2013).

Against this background, issues of governance and institutional coherence turn out to be relevant for our inquiry into the role of culture in social cohesion at the grassroots.

\section{Capacity challenges in addressing climate-driven rural conflicts}

Climate change has been described as a "threat-multiplier" that may intensify existing social, economic, political and environmental problems that communities are already facing. Impacts of climate change are predicted to exacerbate grievances; overwhelm coping capacities; and, in extreme times, spur forced or proactive migration (WBGU, 2008; Yanda and Bronkhorst, 2011). Climate change predictions for Africa suggest increasing scarce water resources associated with declining and failing agricultural yields in the Horn of Africa (Carius, 2009). Some studies predict a significant increase in armed conflicts in sub-Saharan Africa by 2030 compared to the 1980-2000 period (Burke et al., 2009; Lobell et al., 2008) though others challenge this claim (Buhaug, 2010; O'Loughlin et al., 2012). Various studies find mixed results on the climate-conflict link in East Africa (Ide et al., 2014; O'Loughlin et al., 2012; Raleigh and Kniveton, 2012; Schilling et al., 2012; Witsenburg and Adano, 2009).

Land is not just a material resource that people compete over, but it also forms the basis of a particular way of life (farmer, pastoralist, fisher etc.); gives an ethnic identity; and defines gender and age roles (Mwanika, 2010). Figure 1 illustrates possible paths to conflicts induced by climate change in a typical rural village scenario in Kenya. These paths are termed as conflict constellations which are divided into four, namely, water stress, food insecurity, storm and flood disasters, and migration issues (WBGU, 2008; Ossenbrügge, 2009). Cumulative impacts from climate change on key rural livelihood activities, such as agriculture and wildlife tourism, subsequently decrease (or cause failed) harvests and also increase farm raids by wildlife from neighbouring protected lands. Subsequent loss of income in rain-dependent communities lowers the spending power and increases local poverty levels. This affects the vulnerability of households with land as their main asset and additional source of income, especially for rural households experiencing poor harvests and livestock productivity in Kenya (Ntiati, 2002). Consequently, subdivision and sale of land to "outsiders" due to their per- 


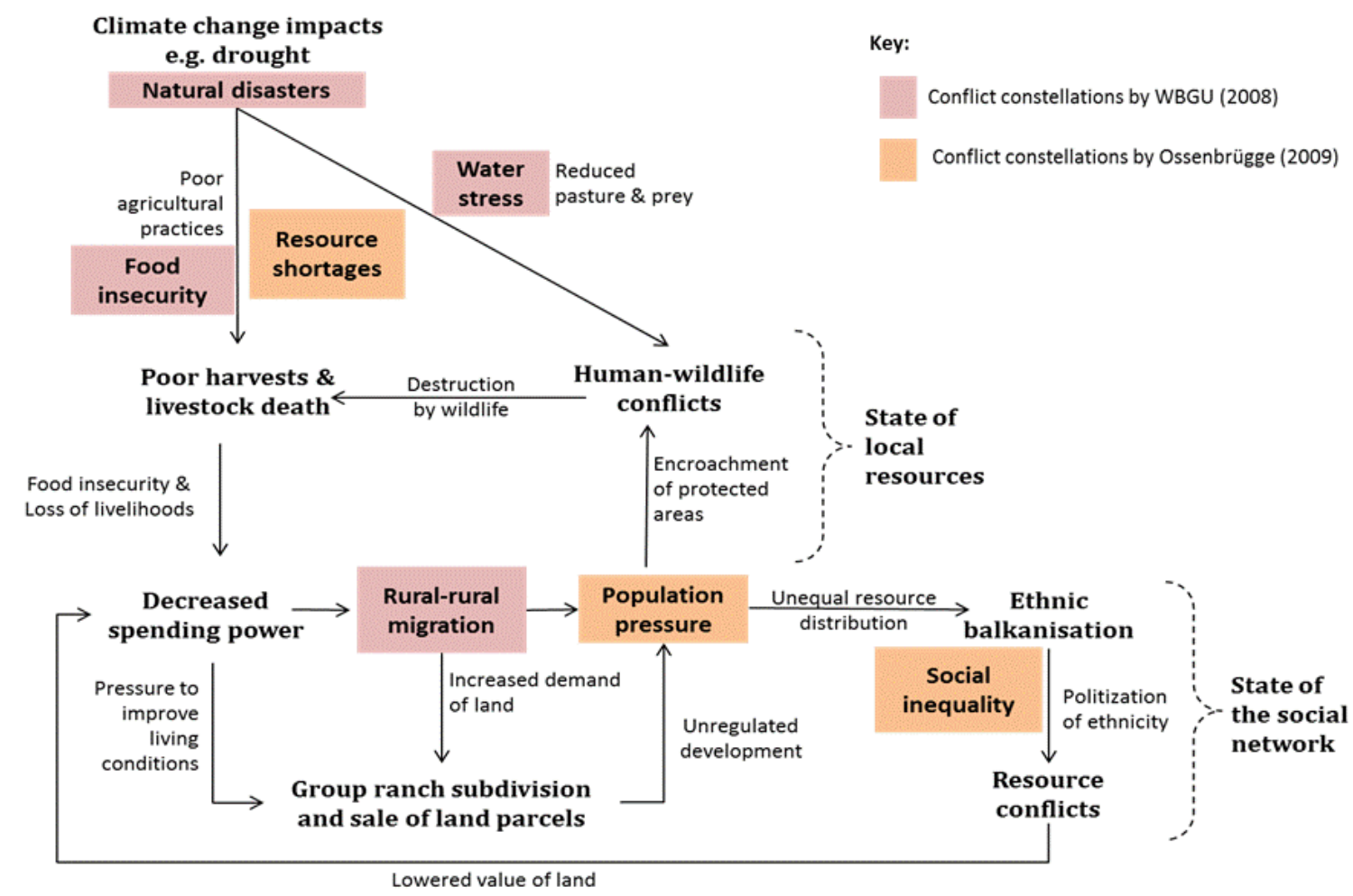

Figure 1. Conflict constellations in relation to climate change and rural land tenure. Source: the authors.

ceived higher capability of enhancing the economic status of the "locals" disrupts the cultural norms and trusts of indigenous host communities through exposure to dissimilar immigrant norms and attitudes.

On the one hand, introduced norms could be beneficial like reduction of female genital mutilation. On the contrary, immigrants are perceived as "threats" who reduce power and influence of tribal chieftains, elites or local politicians. Such divisive thinking is grounded on the parochialism of communities in conceding the rights and interests of other communities (Western, 1994). In the extreme, if civic education is not foremost in the community then such a fragile "host vs. immigrant" situation creates fertile grounds for mobilizing citizens along ethnic or cultural lines by politicians vying for elective posts by promising "equal" resource allocation. Subsequently, people may retreat to their ethnic cocoons and agitate for social respite from the government. Such a "domino" effect clearly demonstrates the link between climate change impacts and resource conflicts whereby a decrease in ecosystem services production leads to increased rural poverty that gradually draws ever-deeper lines of division in social relations and triggers resource conflicts (WBGU, 2008). Hence, the sale of land to "outsiders" leads to reduced land holdings, reduced grazing area, increased incidences of overgrazing, fencing - all of which lead to reduced adaptive capacity. In the absence of conflict-sensitive adaptation programs, these resource conflicts become cyclic and reduce the ability of the community to adapt.

Adaptation funding is already being made available and adaptation projects are under way in many rural communities (Yanda and Bronkhorst, 2011). However, escalating cases of resource conflicts are projected to overwhelm rural conflict resolution mechanisms and reinforce the trend towards general instability and insecurity that already exists in many societies and regions (WBGU, 2008). We find that this prognosis is supported by three main capacity concerns drawn from the literature on climate change and resource conflicts in Africa:

a. Handmer et al. (1999) posit that poorer regions and countries will have difficulty in adapting to climate change, since they lack comprehensive technical and financial ability. In addition, African governments are faced with other major developmental issues such as conflict, diseases and poverty that require direct engagement by the state (AMCEN, 2011). Hence, at the moment climate change adaptation policies seem unlikely to be successful or minimize inequality in Africa.

b. Adaptation is not just a technical process but also a political process since power relations need to be adjusted for individuals and groups to achieve discrete interests to maintain their own livelihoods (Eriksen and Lind, 2009). Poor understanding of the African society struc- 
ture and preference for "foreign" non-governmental organizations (NGOs) with disparate interests in formulating the African adaptation agenda has resulted in poor representation of the grassroots level in the climate discourse, yet they are the most affected group (Hellmuth et al., 2007; Madzwamuse, 2010).

c. Poor representation subsequently creates the third capacity challenge of marginalization of customary law in climate change policy-making at both national and international levels, despite the high significance of indigenous knowledge in the African society (AMCEN, 2011). Moreover, education systems also neglect indigenous knowledge in school curricula concerning environmental studies due to the negative undertone given to cultural practises by colonial governments.

These three adaptive capacity issues infer that coherence between governance institutions is critical in preventing competition over resources turning into a violent conflict (Adano et al., 2012; Young, 2011). This is because effective adaptation can also serve as a "threat minimizer" that brings together actors from security arrangements, conflict resolution and asset management sectors to strengthen local adaptive capacity while reducing predicted conflict cases (Donnelly-Roark et al., 2001). Furthermore, opportunities for incorporating climate information into development activities in sub-Saharan Africa are largely being missed at the moment (Hellmuth et al., 2007). This is mainly because selecting representatives in resource governance institutions becomes a complicated process since African rural communities are composed of diverse informal interest groups that are formed as forums for exchanging knowledge, accessing development funds and markets for their products (Ngaruiya and Scheffran, 2013).

\section{Use of social network theory in resource governance studies}

Incorporation of social network analysis into resource governance has rejuvenated studies in natural resource management by introducing a quantitative approach to political, economic or social processes in connection to structural and environmental processes (Bodin and Prell, 2011). A social network is composed primarily of interdependent actors together with the social relations (ties) linking these actors together for transfer or flow of resources (Bodin and Prell, 2011). Social networks can be viewed as a graph that consists of nodes (actors) joined by lines (relations) which allows researchers to uncover patterns that might otherwise go undetected (Prell et al., 2010). Network analysis fundamentally differs from standard social science research because rather than focusing on attributes of autonomous individual units; it views characteristics of the social units as arising out of structural or relational processes to reveal theoretical moti- vations behind social relationships that shape environmental outcomes (Wasserman and Faust, 1994).

Of interest to this study is how social network analysis facilitates identification of stakeholder positions in a network and how these actors link various parts of the network together (Bodin and Prell, 2011; Ngaruiya et al., 2015). Several mathematical indices are used to quantitatively define this importance or prominence of an individual actor within their social network. Equation (1) defines the betweenness centrality index that counts the number of network pathways passing through an actor and is used to measure how much potential control an actor has in disseminating accurate and relevant information across the community network.

$C_{\mathrm{B}}(k)=\sum_{i \neq j \neq k} \frac{\partial_{i k j}}{\partial_{i j}}$,

where $C_{\mathrm{B}}(k)$ is the betweenness centrality of actor $k, \partial_{i k j}$ is the number of paths linking actors $i$ and $j$ that pass through actor $k$, and $\partial_{i j}$ is the number of paths linking actor $i$ and $j$.

This definition is based on the assumption that interactions between two nonadjacent actors might depend on other actors, especially the actors who lie on the path between the two (Wasserman and Faust, 1994). A practical implication of this index is that if actors rest between many others, then they have the ability to "broker" adaptation information to other actors and thereby influence the level of collective knowledge in the community. If brokers are active within a community, they will not only influence the quantity of knowledge but will also enhance the quality of knowledge circulating because they are able to connect diverse stakeholders to solve a common resource problem. For example, if a community has well-equipped brokers then the local ability to adapt to climate change increases the potential for peaceful conflict resolution and conflict transformation (Tänzler et al., 2013). On the other hand, unrestrained brokerage can create organization chaos, manifest in errors such as resources allocated to conflicting goals and units in the same organization competing against one another (Burt, 2011). A practical example of poor brokerage is how immense adaptation funding has caused a proliferation of actors offering diverse "expertise" in rural communities but with poor performance outcomes in many rural areas (Madzwamuse, 2010). Despite this flaw, brokerage is an interesting concept that is yet to be exhaustively applied in resource governance in Africa.

For that reason this paper uses social network analysis concepts to evaluate rural conflict resolution mechanisms, their structure and how central actors can be used to implement conflict-sensitive adaptation strategies at the grassroots.

\section{Method}

\subsection{Area description}

Our area of focus is Loitoktok Sub-County in Kajiado County, located at the southern tip of the former Rift Valley 
province in Kenya and covers ca. $6356.3 \mathrm{~km}^{2}$. It is situated between longitudes $36^{\circ} 5^{\prime}$ and $37^{\circ} 5^{\prime} \mathrm{E}$ and between latitudes $1^{\circ} 0^{\prime}$ and $3^{\circ} 0^{\prime} \mathrm{S}$ and borders the Republic of Tanzania to the West adjacent to Mt. Kilimanjaro (Government of Kenya, 2009). Ecologically, it is categorized among the arid and semi-arid areas in Kenya. The first census in 1962 showed a population of 24027 persons while the current estimated population for 2012 is 171520 persons. The Sub-County has an estimated annual population growth rate of $4.51 \%$ as per last census count (Government of Kenya, 2009). Loitoktok was formerly known as a district but changed into a SubCounty following promulgation of the 2010 constitution that created new administrative units consisting of Counties and Sub-Counties.

Loitoktok was selected as representative of a typical Kenyan rural area because of (a) its vibrant water, agriculture, and wildlife sectors, (b) rapid land subdivision, (c) introduction of diverse cultures by immigrants with different livelihood practises apart from pastoralism of the Maasai community. In addition, evidence of environmental impacts related to climate change have locally been documented through changes in precipitation (Thompson et al., 2009), temperature fluctuations (Altmann et al., 2002), wildlife mortality (Wangai et al., 2013) and agricultural production (Ngaruiya, 2014) in Loitoktok.

In terms of governance institutions and stakeholder diversity, Loitoktok's rich wildlife supports a strong tourism sector characterized by many hotels and lodges and is rated as one of the key wildlife tourism areas in Kenya. Interestingly, unmonitored land subdivision and climate variability, increased cases of wildlife poaching and human-wildlife conflicts also created opportunities for establishment of several wildlife organizations promoting conservation of local biodiversity. Additionally, due to the Sub-County's' remote and semiarid location, several non-governmental organizations were started to boost the education, water and health sectors in collaboration with government agencies.

\subsection{Data collection and analysis}

Field work was conducted in March-May and OctoberDecember 2012. Information was sought on the resource conflict resolution process for water, wildlife and agriculture sectors. A simple questionnaire collected relational (social network) data of actor linkages using the saturation sampling technique within the Loitoktok community. A respondent was asked to name five persons they share collaborations with during conflict resolution and resource governance, whereby the named actors were located (where possible) and asked to name their collaborators, which went on until no new names were mentioned.

Thereafter, the social network data were converted into an actor matrix and analysed for brokerage using the algorithm for betweenness centrality that finds the geodesics in the network and then computes potential connections of every actor in the community. The resultant data were then visualized as a sociograph using $\mathrm{NetDraw}^{\mathrm{TM}}$ that efficiently illustrates the actual situation at the grassroots (Borgatti et al., 2002).

\section{Results and discussion}

The respondents comprised of 152 persons drawn from four sectors (water, agriculture, wildlife tourism and community) and also included expert interviews in Nairobi, Kajiado and Loitoktok towns. The questionnaire also guided six group discussions in Loitoktok All respondents agreed that inclusion of culture in the conflict resolution process gave the community confidence in decisions agreed after deliberations and that the main aim of a conflict resolution was to reduce tension or violence by bringing the conflicting parties together. This coincides with principles of natural resource management that emphasize the need for cooperation as a necessary precondition for sustainable conflict resolution.

Table 1 illustrates practically how different resource conflicts were resolved between November 2011 and November 2012 at Oloolopon Division in Loitoktok. It is evident that resolving resource conflict is not the responsibility of a single person or institution, but that minor conflicts were resolved by a small stakeholder meeting that was trusted to recommend fair decisions for aggrieved parties, e.g. conflict over water at Impriron. The most recommended discipline measure is compensation by the guilty actors to the aggrieved party according to the level of destruction or damage. In extreme cases, when the community felt aggrieved and the situation was thought to likely spread community tension, the chief was obligated to call for joint meetings (barazas) for all relevant stakeholders and the entire community.

This real-life reflection confirms that chiefs and other traditional authorities also have the potential to mitigate ethnic conflicts by applying traditional conflict-resolution mechanisms to narrow differences (ECA, 2007). The survey also confirms coherence among the different institutions involved in resource conflict resolution.

\subsection{Rural conflict resolution schemes}

Three main conflict resolving systems borne from cooperative efforts were identified in Loitoktok (Fig. 2). These are the following:

\section{a. Policy-guided conflict resolution plan}

Water scarcity was identified as a driver for resource conflict, especially during the dry seasons in Loitoktok. As stipulated in the Water Act of 2002, the Ministry of Water mandates its local government agency - Water Resources Management Authority (WRMA) - to resolve local water conflicts together with the Water Resource Users Association (WRUA). The local chief is an optional mediator in the presence of water officials. If the conflict is not resolved through 
Table 1. The annual resource conflict report of Chief Leonard Kasine in-charge of Oloolopon Division in Loitoktok Sub-County (WRMA: Water Resources Management Authority, KWS: Kenya Wildlife Service).

\begin{tabular}{|c|c|c|c|c|}
\hline Resource & No. of conflicts & Conflict site & Resolution & Stakeholders involved \\
\hline \multirow{3}{*}{ Water } & 3 & Shurie & Compensation & Council of elders, Chief and residents \\
\hline & 7 & Impiron & Community discussion & WRMA and Chief \\
\hline & 1 & Airstrip & Community discussion & Nolturesh Water Board and Chief \\
\hline \multirow{3}{*}{ Livestock } & 16 & Korinko village & Fine after agricultural assessment & Agricultural extension officers, police, Chief \\
\hline & 26 & Inkariak-Rongena & $\begin{array}{l}4 \text { fined by court, } 22 \text { fined after } \\
\text { agricultural assessment }\end{array}$ & Agricultural extension officers, police, Chief \\
\hline & 11 & Kamukunji & Compensation to farmer & Agricultural extension officers, Chief \\
\hline \multirow{2}{*}{ Wildlife } & 30 & Sompet & Compensation & KWS, Private investor - Elephant Research Org. \\
\hline & 6 & Ilmisigiyio & Compensation & KWS, African Wildlife Foundation \\
\hline
\end{tabular}

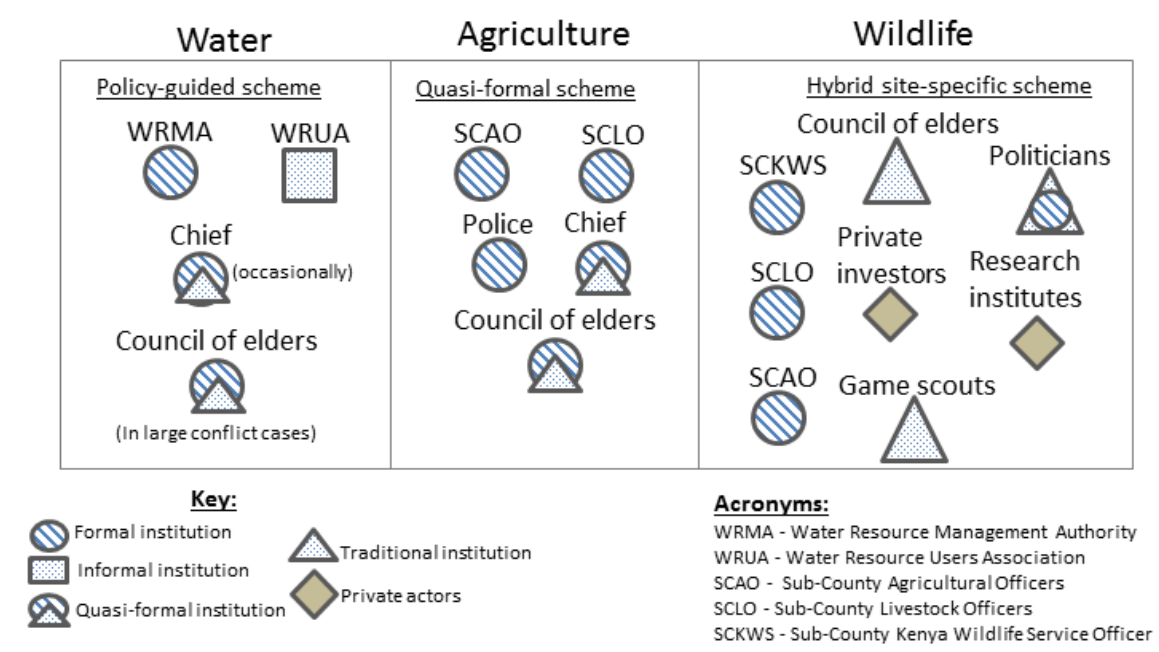

Figure 2. The diverse resource conflict resolution schemes in Loitoktok Sub-County.

negotiation then it is either forwarded to the courts for legal action against the offender or to the Water Appeals Board for further arbitration. An interesting aspect is that WRMA also gives grants to approved WRUA's projects that target enhanced water supply and quality. This clearly has encouraged the community to participate in the prescribed regular training sessions for enhancing local water governance.

Evidently, a well-formulated resource policy is recognized as the first key step in effectively resolving resource conflicts at the grassroots level. Thus the Water Act clearly sets out the conflict resolution process and also empowers the resource users with knowledge of their rights as resource users. For example, Loitoktok WRUA members undertake citizen arrests of persons breaking water laws, especially upstream farmers who over-extract water.

\section{b. Quasi-formal conflict resolution plan}

This structural arrangement is predominantly used to solve two forms of conflict that affect agricultural output. These are the following: (i) human-wildlife conflicts that occur when wildlife invades farms for fodder or livestock (prey) and/or to access water sources. (ii) Farmer-pastoralist conflicts that occur when livestock destroy crops while trying to access watering points since communal grazing areas have been lost following subdivision of community group ranches. The agricultural conflict resolution committee comprises of the formal council of elders (administrative type), the local chief, agricultural extension officers and police. This arrangement is termed as quasi-formal because the elders and chief are nominated from the community by the government, unlike in the water sector that only works with civil servants in conflict resolution. The committee uses a crop damage or livestock death report prepared by the extension officer to guide negotiations after which the aggrieved party is compensated either in kind (livestock) or in cash form. Police is involved to ensure that the conflict resolution process can be transferred to court if the offender fails to fulfil the stipulated compensation. Though the council of elders is part of the community sometimes the community perceives their unfavourable rulings with suspicion as if they represent the government. 


\section{c. Hybrid site-specific conflict resolution plan}

The wildlife sector exhibits a unique conflict resolution strategy as a result of inadequate government policies. This strategy comprises the traditional council of elders, formal government agencies, private investors and researchers who come together to cover shortcomings of the wildlife conflict management strategy. For example, previous absence of compensation for livestock deaths and crop destruction by wildlife led to wanton slaughter of lions, elephants, or zebras. Now, modest payments to aggrieved families by private investors such as Mr Luke of Olkeri Sanctuary for losses incurred by predators or elephants have reduced cases of revenge wildlife killings. Another example was seen at the Mbirikani group ranch whereby game scouts (members of the community) conduct regular patrols. Respondents stated that since the community wildlife policing project has begun, the poaching levels have been reduced. This site-specific measure infers that community members are prone to cohesively use their own knowledge if they are assisted in developing an efficient way of collaboration to enhance their livelihoods.

Though this mechanism seems to be effective, it does not comprehensively deal with the fundamental cause of humanwildlife conflicts. This is because no policy exists on how to ensure survival of wildlife during drought episodes to prevent the recurrent human-wildlife conflicts. In addition, poor understanding of the wildlife management policy has also exposed the community to manipulation by politicians seeking voter mileage at the expense of the human-wildlife incidents.

From this study, it is evident that the resource conflict resolution process involves interaction among diverse actors which in turn increases local civic knowledge, community participation and shows respect to cultural practices that together strengthen rural community networks. This also signals effectiveness of the fusion between indigenous and conventional conflict resolution mechanisms. Furthermore, integration of diverse stakeholders provides a basis to broaden institutional networks and partnerships through alternative livelihood activities that may boost the local economy. However the need to overhaul the land policy in Kenya cannot be overlooked. Respondents stated that a comprehensively developed land policy will establish zones for different development purposes and allocate buffer zones to reduce incidences of encroachment and human-wildlife conflict in protected areas. This action will ensure that future urban expansion will not lead to resource competition or unequal distribution in rural areas of Kenya.

\subsection{Loitoktok social governance structure}

Scrutiny of the resource governance and conflict resolution structures reveal 86 actors in 23 formal institutions (government agencies), 16 informal institutions (community groups), 46 private organizations and 1 traditional institu- tion. These institutions belong to four main sectors namely, agriculture, wildlife and forestry, water resources and community management that implement resource governance through collaborative actions from 30, 31, 11 and 14 actors from the respective sectors.

Figure 3 gives an illustration of how actors are connected and also identifies actors who occupy the central position in Loitoktok. Full names of actors are contained in the supplement. These actors are more visible, have the highest degree of ties and are involved centrally in resource conflict resolution in the network. They include the following: SubCounty Agricultural Officer (SCAO), Sub-County Kenya Wildlife Service (SCKWS) Officer, Sub-County Livestock Officer (SCLO), Sub-County Government (SCG) Officer, Social Development Officer (SDO), Sub-County Water Officer (SCWO), Sub-County Kenya Forest Service (SCKFS) Officer and game scouts. The calculated betweenness scores that indicate the network influence of the identified central actors are $718.5,670.5,179.5,165,151,80,78$ and 78 , in the same order respectively. These values represent currently missing links to neighbouring actors that can be potential links available for each actor to use in increasing the number of connection in the network. The eight actors have the highest ability to build resource knowledge and ecosystem dynamics so that the community can collectively respond to environmental feedback in a fashion that contributes to resilience. The rest of the actors have betweenness scores of less than 10 and thus have a small effect on information dissemination and control within the larger community.

By empowering the central actors to actively create connections that span across different resource sectors then the community can strengthen the local governance strategy for effective problem-focused community resource management. This is discussed below.

\subsection{Building conflict-sensitive adaptation}

Conflict resolution is critical to adaptation as conflict restricts many drought adjustments involving peaceful interaction between many diverse stakeholders. Conflict-sensitive adaptation becomes therefore a holistic, multi-scaled and multisectored approach that taps into the wealth of traditional knowledge regarding the management of resources and conflicts at a community level (Yanda and Bronkhorst, 2011). Conflict-sensitive adaptation processes must be approached using a multi-dimensional system that incorporates different levels, both administrative and societal (Tänzler et al., 2013). This study postulates that central actors, who hold the network together in times of distress, also have potential to influence adaptation information quality and flow in the network.

Loitoktok actors who should be equipped with adaptation knowledge to "broker" to the community are the following: 


\section{Loitoktok resource governance network}

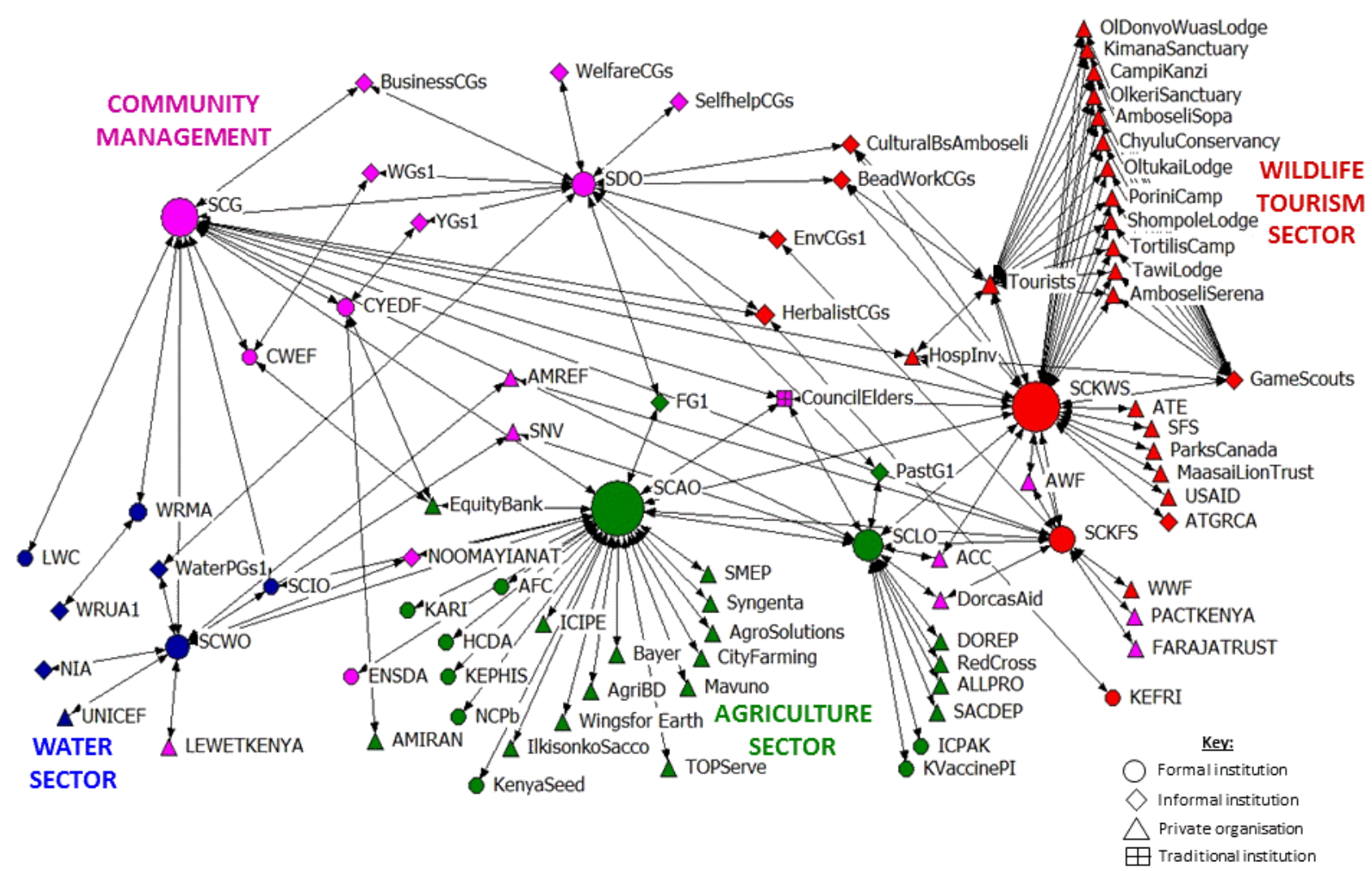

Figure 3. Social network illustrating actor linkages in resource governance at Loitoktok community.

\section{a. Extension officers}

These are the Sub-County Agricultural Officer (SCAO), SubCounty Livestock Officer (SCLO), Sub-County Kenya Forest Service (SCKFS) Officer and Sub-County Kenya Wildlife Service (SCKWS) Officer. The extension officers are well connected to their respective community interest groups (informal institutions) and thus can be effective in transfer of adaptation knowledge. The community indicated that water and wildlife sectors recorded the highest number of conflicts and subsequent studies have confirmed low adaptation measures in these two sectors. Conversely, crop and livestock sectors have the most diverse adaptation measures due to a close public-private actor partnership (Ngaruiya, 2014). Therefore, specialized training of extension officers in adaptation technology and water harvesting for subsequent transfer to the community will not only buffer food security (crop and livestock products) but will also strengthen the local economy through creation of additional livelihood opportunities in a climate change context.

\section{b. Council of elders}

In Loitoktok, the outstanding traditional institution is the Council of Elders that is made up of persons of integrity and objectivity who have distinguished themselves in one way or another and have been recognized as such by the community (Cheka, 2008). There are two types of Council of Elders. First, the Council of Elders that is appointed by the State and is made up of men from the three major tribes in the Sub-County to help in administration issues such as immigration and conflict resolution in the agriculture sector (quasi-formal). Secondly, the dominant host Maasai community exclusively selects its indigenous Maasai Council of Elders (traditional institution) according to its culture which is also respected by other communities in Loitoktok. This council is highly regarded in the wildlife sector where it plays a key role in either agitating for action by the government and investors or calming the Maasai community after a serious human-wildlife incident. Interestingly from the social network analysis, the council of elders is not among the top central actors because of the administrative dichotomy in the Sub-County. But the fact still remains that they are well connected to each resource sector, thereby giving them a stronger knowledge dissemination power in the community. 
In terms of judgements and costs, indigenous conflict resolution mechanisms have been found to be effective for both lesser criminal cases such as stock theft, land disputes and serious crimes such as genocide as seen in Rwanda (ECA, 2007). Hence incorporating such respected institutions originating from customary law and indigenous knowledge into climate change policies is likely to result in formulation of effective adaptation strategies that will be participatory and highly acceptable by the rest of the community.

\section{c. Local chief}

Loitoktok has 16 locations each governed by a chief and 31 sub-chiefs who are in-charge of sub-locations. These chieftaincy positions are not elective but the person is nominated by the government to participate in decision-making at the grassroots. The chiefs work under the Sub-County Government (SCG) office and are called upon by the government depending on the conflict situation in the community. The administrative council of elders also falls under the SCG office as a physical representation of the government in the community. These quasi-formal arrangements are alternative institutions that are peripherally involved in resource governance but can also improve the climate change discourse in Africa. The chiefs and council of elders can identify isolated rural community interest groups for training in resource governance including conflict resolution since unmanaged informal groups form many small and dense clusters with little or no diversity and little adaptation knowledge that become resistant to change. An example is pastoralists who view livestock as a form of wealth and calls by extension officers to dispose of healthy animals before onset of drought are viewed with suspicion. Furthermore, chiefs can conduct civic lessons among their constituents as a means of promoting integration and coexistence and dispelling false information to foster the concept of "a common people with a common destiny" (Aapengnuo, 2010).

\section{d. Private investors and researchers}

The Loitoktok network has many private organizations such as hotel owners, seed companies' researchers, humanitarian workers etc. in all the resource sectors. Most private actors are seen to be more effective in resolving conflicts in the wildlife sector as a way of preserving the wildlife resource that attracts tourists to the area. Societal decision-making is nested in a wider set of societal changes, such as institutional changes and altered relations between public and private actors. Thus, for a community to increase its adaptive capacity then it should incorporate all stakeholders in developing land and resource management designs to make them more effective and relevant to investors. Apart from formal institutions and the non-governmental organizations, communities should incorporate local investors who have financial and technical ability to support the community in sustain- able use of biodiversity and practical knowledge to maintain ecosystems in good condition to avoid conflicts over scarce resources especially during drought.

\section{Conclusions}

A number of studies have used economic, political and ecological aspects to expound resource conflicts in several African countries. However, few studies (some of which are discussed in Sect. 2.1) have documented the social structures that induce or resolve conflicts at the grassroots. This study confirms that in post-colonial Kenya, resource governance still contains vestiges of traditional institutions, especially in collective discussion of grievance towards effective conflict resolution. The innovative arrangements make use of indigenous knowledge to calm the aggrieved and agitate for compensation by the government. As a result, this integration binds the society together by its inherent customs based on brotherhood notions for enhanced resource utilization and livelihoods, regardless of climatic conditions.

Secondly, climate change threatens to disrupt conflict resolution mechanisms that are operational in rural centres because of capacity challenges associated with Africa's low technical ability to manage climate governance, poor integration of diverse opinions and marginalization of indigenous knowledge into adaptation and mitigation agendas. We based the field study on the Loitoktok Sub-County that is expanding in terms of its cultural diversity, economic sectors and profile of resource conflict which is representative of many rural areas in Kenya as well as sub-Saharan countries. Results indicate that conflict resolution was achieved through three forms of institutions, each unique to its natural resource. The water sector relied upon its comprehensive policy; agriculture used a quasi-formal arrangement while the wildlife sector formulated its own hybrid arrangement that involved private investors and the traditional council of Maasai elders. In extreme cases, the community came together in barazas to air their concerns and agree on a collective decision acceptable to all relevant stakeholders.

Implementation of conflict-sensitive adaptation requires a deep understanding of the context in which climate-driven resource-conflicts are resolved in a community and clearly delineated actor interactions between local resource-related activities. Therefore, we used the betweenness centrality index drawn from the flourishing field of social network theory to evaluate the central actors with potential to broker adaptation knowledge across the Loitoktok network. Results indicate that extension officers, council of elders, local chief and private investors are the suitable central actors who should be financially and technologically equipped for building conflict-sensitive adaptive capacity in the community. Thus government and non-government stakeholders must work together to identify risks and formulate strategies and programmes that can help raise awareness among civil society of the impact of climate change. 
As a contribution to the climate and security discourse, this study advocates for two adaptive co-management measures to help overcome climate change-related capacity challenges at the grassroots in Africa. First, clear conflict resolution policy in natural resource governance as seen in the water sector will help solve local conflicts and also enable stakeholders to understand local conflict genesis and effectively prepare for unpredictable climatic conditions. Secondly, involving diverse actors from the community in resolving conflict as seen in the wildlife sector, also has potential in serving as a conduit of the adaptation knowledge sector that empower the community despite policy inadequacies. Moreover, traditional institutions like the council of elders have been seen as a source of civic knowledge, and encourage respect of local values and customs that contribute to community selfreliance and empowerment in the community.

To conclude, natural resource regulations and governance arrangements play important roles in handling potential conflicts over scarce natural resources, particularly water in arid and semi-arid lands (ASAL). Thus resource conflict resolution and positive culture transmission should be part of an effective conflict-sensitive adaptation strategy. These two aspects encourage growth of cohesive social capital that in turn enhances economic development at the grassroots and effective governance of the commons.

\section{The Supplement related to this article is available online at doi:10.5194/esd-7-441-2016-supplement.}

Acknowledgements. Special thanks go to Mr. Gadayo (Wiper), John W. Kiringe and Paul Ngugi (Treasury) for assistance in Kenya. This work is supported by DeutscherAkademischerAustauschdienst (DAAD), National Council for Science and Technology (NCST)Kenya, German Science Foundation (DFG) through Cluster of Excellence "Integrated Climate System Analysis and Prediction", and School of Integrated Climate System Sciences (SICSS) as a $\mathrm{PhD}$ project at the University of Hamburg, Germany.

Edited by: T. Brücher

\section{References}

Aapengnuo, C. M.: Misinterpreting ethnic conflicts in Africa, Africa Center for Strategic Studies, Washington, DC, Africa Security Brief No. 4, 6 pp., Available at: http://africacenter.org/ 2010/04/misinterpreting-ethnic-conflicts-in-africa/, last access: 20 October 2015, 2010.

Adano, W. R., Dietz, T., Witsenburg, K., and Zaal, F.: Climate change, violent conflict and local institutions in Kenya's drylands, J. Peace Res., 49, 65-80, 2012.

Altmann, J., Alberts, S. C., Altmann, S. A., and Roy, S. B.: Dramatic change in local climate patterns in the Amboseli basin, Kenya, Afr. J. Ecol., 40, 248-251, 2002.
AMCEN: Addressing Climate Change Challenges in Africa: A Practical Guide towards Sustainable Development, African Union Commission \& United Nations Environment Programme Secretariat, Nairobi, Kenya, 2011.

Berkes, F.: Rethinking community-based conservation, Conserv. Biol., 18, 621-630, 2004.

Bodin, Ö. and Prell, C.: Social Networks and Natural Resource Management: Uncovering the Social Fabric of Environmental Governance, Cambridge University Press, Cambridge, UK, 2011.

Borgatti, S. P., Everett, M. G., and Freeman, L. C.: Ucinet for Windows: Software for Social Network Analysis, Analytic Technologies, Harvard, MA, available at: https://sites.google.com/ site/ucinetsoftware/, last access: 10 March 2015, 2002.

Brunner, R. D., Steelman, T. A., Coe-Juell, L., Cromley, C., Edwards, C., and Tucker, D.: Adaptive governance: integrating science, policy, and decision making, Columbia University Press, New York, 2005.

Buhaug, H.: Climate not to blame for African civil wars, P. Natl. Acad. Sci. USA, 107, 16477-16482, 2010.

Burke, M. B., Miguel, E., Satyanath, S., Dykema, J. A., and Lobell, D. B.: Warming increases the risk of civil war in Africa, P. Natl. Acad. Sci. USA, 106, 20670-20674, 2009.

Burt, R.: Brokerage and closure: an introduction to social capital, 2nd. Edn., Oxford University Press, Oxford, New York, 2011.

Carius, A.: Climate Change and Security in Africa: Challenges and international policy context, United Nations, Berlin, Germany, 2009.

Cheka, C.: Traditional Authority at the Crossroads of Governance in Republican Cameroon, Africa Development, 33, 67-89, 2008.

Donnelly-Roark, P., Ouedraogo, K., and Ye, X.: Can Local Institutions Reduce Poverty? Rural Decentralization in Burkina Faso, Policy Research Working Paper Series, The World Bank, Africa Region, Environment and Social Development Unit, Washington, DC, Working paper no. 2677, 52 pp., 2001.

ECA: ADF IV: Governance for a Progressing Africa, Economic Commission for Africa, Addis Ababa, Ethiopia, 2005.

ECA: Relevance of African Traditional Institutions of Governance., Economic Commission for Africa, Addis Ababa, Ethiopia, 2007.

Eriksen, S. and Lind, J.: Adaptation as a political process: Adjusting to drought and conflict in Kenya's drylands, Environ. Manage., 43, 817-835, 2009.

Folke, C., Hahn, T., Olsson, P., and Norberg, J.: Adaptive governance of social-ecological systems, Annu. Rev. Env. Resour., 30, 441-473, 2005.

Government of Kenya: Loitoktok District Development Plan, Office of the Prime Minister, Ministry of Planning National Development and Vision 2030, Nairobi, Kenya, 2009.

Haldén, P.: The Geopolitics of Climate Change: Challenges to the International System, Swedish Defence Research Agency, Stockholm, Sweden, 2007.

Handmer, J. W., Dovers, S., and Downing, T. E.: Societal vulnerability to climate change and variability, Mitigation and Adaptation Strategies for Global Change, 4, 267-281, 1999.

Hellmuth, M. E., Moorhead, A., Thomson, M. C., and Williams, J.: Climate risk management in Africa: learning from practice, International Research Institute for Climate and Society, The Earth Institute at Columbia University, New York, 2007. 
Hyden, G., Court, J., and Mease, K.: Making Sense of Governance: The Need for Involving Local Stakeholders, available at: http://www.odi.org.uk/sites/odi.org.uk/files/odi-assets/ publications-opinion-files/4092.pdf, last access: 6 April 2015, 2005.

Ide, T., Schilling, J., Link, J. S., Scheffran, J., Ngaruiya, G., and Weinzierl, T.: On exposure, vulnerability and violence: Spatial distribution of risk factors for climate change and violent conflict across Kenya and Uganda, Polit. Geogr., 43, 68-81, 2014.

IDRC: Reconciling Africa's fragmented institutions of governance: a new approach to institution building, International Development Research Centre, Human Sciences Research Council and Pennsylvania State University, Willow Park Conference Centre, Kempton Park, Gauteng, South Africa, 2009.

IIDEA: Customary Governance and Democracy Building: Exploring the Linkages, International Institute for Democracy and Electoral Assistance, Stockholm, Sweden, 2011.

IPCC: Climate change 2007-the physical science basis: Working group I contribution to the fourth assessment report of the IPCC, Cambridge University Press, Cambridge, UK, 2007.

Irwin, F. H., Ranganathan, J., and Bateman, M.: Restoring Nature's Capital: An Action Agenda to Sustain Ecosystem Services, World Resources Institute, Washington, DC, WRI Report, 100 pp., 2007.

Lobell, D. B., Burke, M. B., Tebaldi, C., Mastrandrea, M. D., Falcon, W. P., and Naylor, R. L.: Prioritizing climate change adaptation needs for food security in 2030, Science, 319, 607-610, 2008.

Madzwamuse, M.: Climate Governance in Africa-Adaptation Strategies and Institutions, Heinrich Boll Stiftung, Germany, 2010.

Mowo, J. G., Adimassu, Z., Catacutan, D., Tanui, J., Masuki, K., and Lyamchai, C.: The Importance of Local Traditional Institutions in the Management of Natural Resources in the Highlands of East Africa, Hum. Organ., 72, 154-163, 2013.

Mwanika, P. A. N.: Natural resources conflict: management processes and strategies in Africa, International Security Studies, Briefing paper, 216, 12 pp., 2010.

Ngaruiya, G. W.: Does reactive adaptation exist? Using the ecosystem service governance approach to evaluate post-drought rural food security in Kenya, Natural Resources, 5, 392-407, 2014.

Ngaruiya, G. W. and Scheffran, J.: Reducing climate adaptation deficits using revolving fund network schemes in rural areas of Kenya: case study of Loitoktok district, African Journal of Economic and Sustainable Development, 2, 347-362, 2013.

Ngaruiya, G. W., Scheffran, J., and Yang, L.: Social Networks in Water Governance and Climate Adaptation in Kenya, in: Sustainable Water Use and Management, edited by: Filho, W. L. and Sümer, V., Springer, Green Energy and Technology, 151-167, 2015.

Ntiati, P.: Group ranches subdivision study in Loitokitok division of Kajiado District, Kenya, Working Paper, International Livestock Research Institute, Nairobi, Kenya, 2002.

O’Loughlin, J., Witmer, F. D., Linke, A. M., Laing, A., Gettelman, A., and Dudhia, J.: Climate variability and conflict risk in East Africa, 1990-2009, P. Natl. Acad. Sci. USA, 109, 18344-18349, 2012.

Osaghae, E. E.: The Passage from the Past to the Present in African Political Thought:The Question of Relevance in African Tradi- tional Political Thought and Institutions, edited by: Ali, Z. S., Ayoade, J. A. A., and Agbaje, A. A. B., Centre for Black and African Arts and Civilization (CBAAC) Second Seminar Series, Civiletis International, Lagos, Nigeria, 53-75, 1989.

Ossenbrügge, J.: Ressourcenkonflikte in Afrika, Wissenschaft \& Frieden, 2, 15-19, 2009.

Prell, C., Reed, M., Racin, L., and Hubacek, K.: Competing Structure, Competing Views: The Role of Formal and Informal Social Structures in Shaping Stakeholder Perceptions, Ecol. Soc., 15, 34, 18 pp., 2010.

Raleigh, C. and Kniveton, D.: Come rain or shine: An analysis of conflict and climate variability in East Africa, J. Peace Res., 49, 51-64, 2012.

Schilling, J., Opiyo, F. E., and Scheffran, J.: Raiding pastoral livelihoods: motives and effects of violent conflict in north-western Kenya, Pastoralism, 2, 1-16, 2012.

Tänzler, D., Carius, A., and Maas, A.: The Need for ConflictSensitive Adaptation to Climate Change, in: Backdraft: The Conflict Potential of Climate Change Adaptation and Mitigation, edited by: Dabelko, G. D., Herzer, L., Null, S., Parker, M., and Sticklor, R., Woodrow Wilson International Center for Scholars, Washington, D.C., Environmental Change and Security Program Report 14:2, 5-12, 2013.

Thompson, L. G., Brecher, H. H., Mosley-Thompson, E., Hardy, D. R., and Mark, B. G.: Glacier loss on Kilimanjaro continues unabated, P. Natl. Acad. Sci. USA, 106, 19770-19775, 2009.

UNEP: From Conflict to Peacebuilding: The Role of Natural Resources and the Environment, UNEP/Earthprint, Nairobi, Kenya, 2009.

UNEP: Livelihood security: climate change, migration and conflict in the Sahel, UNEP, United Nations Environment Programme, Châtelaine, Geneva, 2011.

Wangai, P., Muriithi, J., and Koenig, A.: Drought Related Impacts on Local People's Socioeconomic Life and Biodiversity Conservation at Kuku Group Ranch, Southern Kenya, International Journal of Ecosystem, 3, 1-6, doi:10.5923/j.ije.20130301.01, 2013.

Wasserman, S. and Faust, K.: Social network analysis methods and applications, Cambridge University Press, Cambridge, New York, 1994.

WBGU: Climate change as a security risk, Earthscan, Sterling, Va., London 2008.

Western, D.: Ecosystem conservation and rural development: The case of Amboseli, in: Natural connections: perspectives in community-based conservation, edited by: Western, D., Wright, R. M., and Strum, S. C., Island Press, Washington, DC, 600 pp., 1994.

Witsenburg, K. M. and Adano, W. R.: Of rain and raids: Violent livestock raiding in northern Kenya, Civil Wars, 11, 514-538, 2009.

WRI, UNDP, UNEP and World Bank: World Resources, 2005: The Wealth of the Poor?: Managing Ecosystems to Fight Poverty, World Resources Institute, Washington, DC, 2005.

Yanda, P. and Bronkhorst, S.: Climate change and conflict: Conflictsensitive climate change adaptation in Africa, ACCORD, Policy \& Practice Briefs, Issue \#014, 6 pp., 2011.

Young, O. R.: Land use, environmental change, and sustainable development: the role of institutional diagnostics, International Journal of the Commons, 5, 66-85, doi:10.18352/ijc.244, 2011. 